\title{
TEMPERATURE AND DEUTERATION EFFECTS ON THE FLUORESCENCE OF BENZENOID SOLUTIONS
}

\author{
L.C. PEREIRA, I.C. FERREIRA * and Marilia P.F. THOMAZ ** \\ Centro de Física e Química, Universidade do Minho, Braga. Portugal
}

Received 3 February 1976

Revised manuscript received 27 April 1976

\begin{abstract}
Deuterium isotope substitution and temperature effects on the fluorescence of toluene and p-xylene solutiors have been investigated. Values of fluorescence quantum yields u'ere measured bet;een $-80^{\circ}$ to $70^{\circ} \mathrm{C}$ for $p$-xylene, $p$-xylene-d 10 , toluene and toluene- $d_{8}$ and also fluorescence decay times at room temperature. The influence of several experimental factors on the fluorescence intensity at various temperatures was investigated and corrections were applicd to obtain correct quantum yields. The results are compatible with an absence of a normal deuteration effect, and are independent of temperature, for both molecules, and show the existence of a non-radiative transition from the first excited singlet state to the ground state.
\end{abstract}

\section{Introduction}

Deurcraiion and temperature effects on photoluminescence have provided, in recent years, valuable information for thi: understanding of radiationless transitions in poly:atomic molecules.

In the riesent work we present and discuss results ciealin:- with the effect of deuterium isotope substitution and temperature on the fluorescence of dilute solutions of toluene and $p$-xylene in ethanol. Several factors affecting the fluorescence intensity have been in. vestigated in detail in order to obtain the correct fluorescence quantum yields.

\section{Experimental}

Toluene, $p$-xylene and ethanol (spectro-quality) and toluene- $d_{8}$ and $p$-xylene- $d_{10}$ (isotopic purity $99 \%$ ) were used without further purification. No impurities were detected in any of the products by luminescence and absorption spectroscopy.

Fluorescence decay times $\left(\tau_{M}\right)$ were measured at room temperature $\left(25^{\circ} \mathrm{C}\right)$ with a conventional pulse

\footnotetext{
- Now at The Royal Institution, London, UK.

- Now at Universidade de Aveiro, Portugal.
}

nuorometer using a high pressure nitrogen lamp for excitation. The exciting radiation and emission were seierted by grating monochromators. Experimental details of the apparatus are described elsewhere [1]. The decay curves of the deuterated and protonated solutions, after saturation with argon, were obtained immediately one after the other, under the same conditions of instrumental response to the light pulse.

The values of $\tau_{M}$ were obtained from experimental data using a computational method as described by Demas and Adamson [2].

Fluorescence quantum yields $\left(\phi_{F M}\right)$ were measured at room temperature in a spectrofluorimeter previously described [3]. From the absorption spectra of the samples and of the standard, previously measured, a narrow bandpass of excitation at a suitable wavenumber was selected which ensures, in each case, the same optical density. The solutions $\left(\approx 10^{-3} \mathrm{M}\right)$ were contained in $a$ spectrosil cell under argon atmosphere and right angle viewing was used. Solutions of toluene in methylcyclohexane and in hexane for which $\phi_{\mathrm{FM}}=0.14$ was previously determined [4] were used as standards.

Polarization effects induced by the apparatus [5] were measured as a function of wavelength. Although considerable at lower energies they are negligible within the range of wavelengths of emission under consideration. 
The measurements of $\phi_{\mathrm{FM}}$ as a function of temperature, below room temperature, was carried out by using a cryostat unit described elsewhere [4] . A specially designed dewar with three spectrosil windows was used to work with right-angle viewing and also in reflection and transmission. A continuous stream of dry nitrogen on the dewar's windows was used to prevent condensation at lower temperatures. For measurements above room temperature an insulated heating block was used. In both cases the temperature was monitored using a temperature meter connected to a recorder and the measurements were taken after convenient temperature stabilization. The solutions were contained in a cell which was sealed off after a convenient number of freeze-thaw cycles of degassing. Alternatively the solutions were saturated with argon and sealed via a special vacuum tap.

Variations of fluorescence intensities with temperature were always measured during both the cooling and heating period and a good reproducihility was achieved $( \pm 2 \%)$. Corrections of the fluorescence intensity due to variations of the refractive index with temperature and solvent were applied [6]. Previous calculations of $n^{2}$ at various temperatures [4] for a wavenumber of about $35000 \mathrm{~cm}^{-1}$ are in good agreement with those used by other authors [7].

Variations of the optical density of the solutions with temperature were monitored by measuring the amount of light transmitted by the solvent and by the sample, at various temperatures, with the same instrumental conditions as for fluorescence measurements. By this method it is also possible to detect whether the solvent is transparent over all the region of temperatures. Solvents not completely transparent at low temperatures were found to produce an anomalous fluorescence intensity, this being attributed to small particles of ice or otiser impurities acting as a diffuse reflector.

Small variations of the intensity of fluorescence due to some degree of polarization were detected at lower temperatures by passing the emission signal through a UV polarizer at different orientations and corrections were applied [8]. The reflectivity of the optical system was found to be constant within the interval of temperatures considered.

\section{Results and discussion}

The results obtained for $\phi_{F M}$ and $\tau_{M}$, at $25^{\circ} \mathrm{C}$, are shown in table 1 where values reported by other authors are also indicated for comparison. The results found for $\phi_{F M}$ are lower than those reported by Berlman [9] particularly in the case of $p$-xylene but are in good agreement with those of Froehlich and Morrison [11] and of Lumb and co-workers $[3,10]$. The results found for $\tau_{M}$ are also in reasonable agreement with those reported by other authors.

The variation of $\phi_{F M}$ with temperature is shown in figs. 1 and 2 , respectively, for the pairs toluene, toluene$d_{8}$ and $p$-xylene, $p$-xylene- $d_{10}$. As expected $\phi_{F M}$ increases on lowering the temperature.

It is generally assumed that a decrease of fluorescence intensity with increasing temperature is due to a greater probability of the transition from the first excited singlet state $\left(S_{1}\right)$ to the triplet manifold. This seems to be well established in molecules for which the sum of $\phi_{F M}$ and triplet yield $\left(\phi_{T M}\right)$ is unity but the situation is different for benzene and its alkyl derivatives [13-15]. Measurements of $\phi_{\mathrm{TM}}$ for those molecules using.either the cis $\rightarrow$ trans isomerization technique of butene-2 [16-18] or

Table 1

Fluorescence quantum yields and lifetimes at roon temperature

\begin{tabular}{|c|c|c|c|c|}
\hline Compound & $\phi_{F M}{ }^{a)}$ & $\tau_{M}{ }^{a !}(n s)$ & $\phi_{F M}{ }^{b)}$ & ${ }^{\top} M^{b)}$ (ns) \\
\hline toluene & 0.13 & 35.0 & $0.17[9] ; 0.12[10]$ & 34 [9] \\
\hline toluene-d $_{8}$ & 0.14 & 36.0 & $0.21[9]$ & $35[9]$ \\
\hline p-xylene & 0.24 & 33.7 & $0.40[9] ; 0.22[11]$ & $30[9] ; 34.5[12]$ \\
\hline$p$-xylene-d 10 & 0.22 & 32.9 & $0.26[9]$ & $30.3[9]$ \\
\hline
\end{tabular}

a) This work. The estimated error for both $\phi_{F M}$ and $\gamma_{M}$ is $\pm S \%$.

b) Other work 


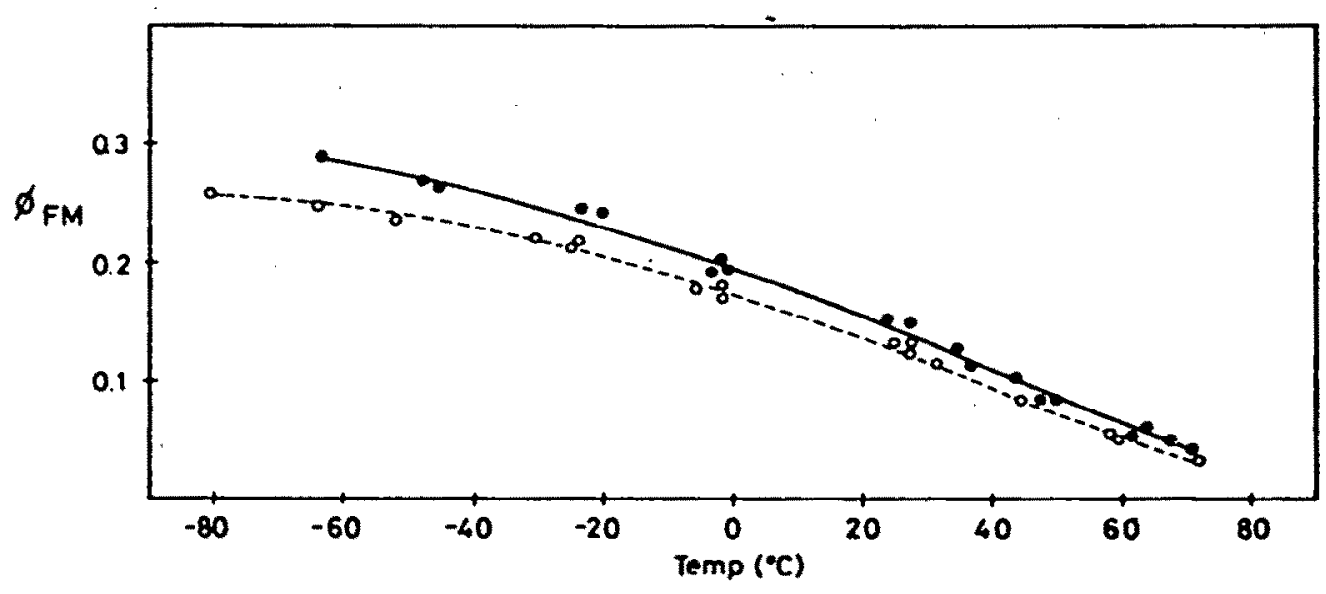

Fig. 1. Fluorescence quantum yields as a function of temperature for toluene $(0)$ and toluened $8(\bullet)$.

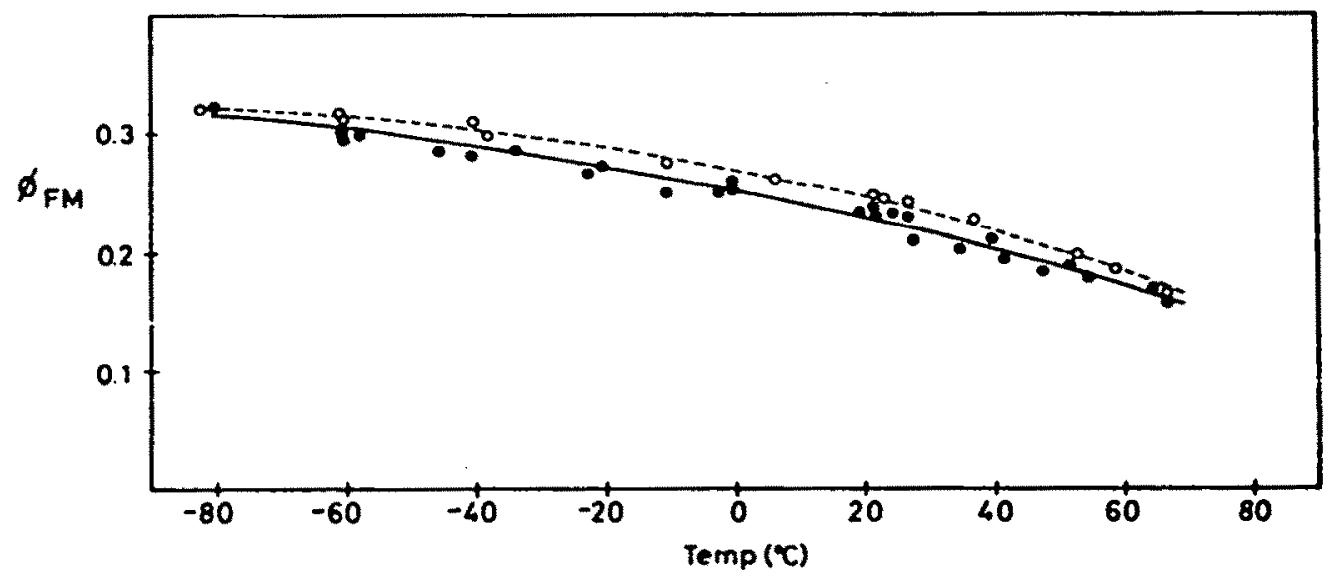

Fig. 2. Fluorescence quantum yiclds as a function of temperature for $p$-xylene $(0)$ and $p$-xylene-d $d_{10}(\bullet)$.

the sensitized biacetyl phosphorescence method [19] have shown the occurrence of a radiationless deactivation of $S_{1}$ in addition to the intersystem crossing process. The origin of this third channel of deactivation is not well established. Calculations based on current theories of radiationless transitions discount the possibility of a direct internal conversion $S_{1} \rightarrow S_{0}$ [20]. However the recently developed tunnel effect model of radiationless transitions [21] applied to benzene predicts the existence of a r.on-radiative channel of relaxation $S_{1} \rightarrow S_{0}$ with a rate constant with the right order of mag. nitude.

The measurement of $\phi_{\mathrm{rM}}$ of dilute solutions of toluene, $p$-xylene and other methylbenzenes $[16,18,22]$, as a function of temperature, have shown that the rate constants for intersystem crossing and nuorescence, respectively $k_{\mathrm{TM}}$ and $k_{\mathrm{FM}}$, are practically independent of temperature and the rate constant for the non-radiative transition $S_{1} \rightarrow S_{0},\left(k_{G M}\right)$ is temperature dependent [16,22].

The radiative rate constant for fluorescence as calculated from table 1 is $3.7 \times 10^{6} \mathrm{~s}^{-1}$ and $4.0 \times 10^{6} \mathrm{~s}^{-1}$ respectively for toluene and toluened $d_{8}$ and $7.1 \times 10^{5}$ $\mathrm{s}^{-1}$ and $6.7 \times 10^{6} \mathrm{~s}^{-1}$ for $p$-xylene and $p$-xylene- ${ }_{10}$. These results show that $k_{\mathrm{FM}}$ is independent of deuteration within experimental error and confirm the so-called xylene effect whereby para-substituents on the benzene ring enhance $\phi_{\mathrm{FM}}$ due to an increase of $k_{\mathrm{FM}}[11]$. 
Using the values of 0.61 obtained by Cundall and Ogilvie [22] for triplet yields of dilute solutions of $p$. xylene in methylcyclohexanc, at $25^{\circ} \mathrm{C}$, one obtains for this molecule at this temperature $\phi_{\mathrm{FM}}+\phi_{\mathrm{TM}}=0.85$, assuming negligible solvent effects.

At temperatures corresponding to the plateau region of $\phi_{F M}$, using our results and the triplet yields determined by Cundall and Ogilvie [22] a value of $\phi_{\mathrm{FM}}+$ $\phi_{T M}=1.06 \pm 10 \%$ is obtained. This shows that as in the case of toluene [16] the non-radiative process $S_{1}$ $\rightarrow \mathrm{S}_{0}$ becomes negligible in the low temperatures region.

Representing the internal quenching of $\mathrm{S}_{1}$ by $k_{\mathrm{IM}}=$ $k_{\mathrm{TM}}+k_{\mathrm{GM}}$, one obtains the following ratios at room temperature

$k_{\mathrm{IM}}^{\mathrm{D}} / k_{\mathrm{IM}}^{\mathrm{H}}=0.99$

for toluene, and

$k_{\text {IMI }}^{\mathrm{D}} / k_{\mathrm{IMI}}^{\mathrm{H}}=1.05$

for $p \cdot x y l e n e$, where the symbols $\mathrm{D}$ and $\mathrm{H}$ refer respec. tively to the deuterated and protonated compounds.

The ratios obtained arc, in each case, ncit far from unity within experimental error. Assuming that $k_{\mathrm{GM}}$ is not sensitive to deuteration, since a direct internal conversion $S_{1} \rightarrow S_{0}$ is improbable [20], our results can be interpreted in terms of an absence of a deuteration effect.

The results obtained show that fuorescence is very little affected by deuteration. Similar results have been described by other authors [20:23] and in some cases a reverse deuteration effect was reported [24]. Results obtained with gaseous benzene are an exception. Using fuorescence lifetimes and fluorescence and triplet yield results, Cundall et al. [14] have reported the values of $7.9 \times 10^{6} \mathrm{~s}^{-1}$ and $11 \times 10^{6} \mathrm{~s}^{-1}$, for intersystem crossing rate constants, respectively, for heavy and light benzene, under high pressure conditions and excitation at 260 nm. Similar effects were reported by other authors [25]. The situation is different for benzene in the liquid phase. Cundall et al. [26] have measured $\phi_{T M}$ and have found respectively the values of 0.235 and 0.250 for dilute solutions of benzene $i_{6}$ and benzene- $h_{6}$ in methylcyclohexane, at $26^{\circ} \mathrm{C}$. Sandros [19] using a different technique has reported respectively $\phi_{\mathrm{TM}}=0.252$ for benzene- $h_{6}$ and $\phi_{\mathrm{TM}}=0.240$ for benzene $d_{6}$ in dilute solutions of cyclohexane, at $20^{\circ} \mathrm{C}$. Using these results and decay iimes reported in the literature $[9,20]$, one obtains $k_{\mathrm{TM}}^{H}=8.7 \times 10^{6} \mathrm{~s}^{-1}$ and $k_{\mathrm{TM}}^{\mathrm{D}}=8.9 \times 10^{6} \mathrm{~s}^{-1}$. which shows no perdeuteration effect on $k_{\mathrm{TM}}$. The differences between gas and liquid phase seem to indicate that in the gas phase the intersystem crossing transition proceeds from ${ }^{1} B_{2 u}$ to both ${ }^{3} E_{1 u}$ and ${ }^{3} B_{1 u}$ states.

As pointed out by Sharf and Silbey [27] and by Birks [15] the reverse deuteration effect is consistent with a dominant $S_{1} \rightarrow T_{q}(q \geqslant 2)$ intersystem crossing. This is expected to happen in molecules in which the transition $S_{1} \rightarrow T_{2}$ is well established and was confirmed in the case of anthracene solutions for which a reverse deuteration effect, disappearing at high temperatures, was found by Lim and Bhattacharjee [24].

The $S_{1} \rightarrow T_{1}$ energy gaps calculated from the literature [20] for toluene and $p$-xylene are in both cases $\approx 8270 \mathrm{~cm}^{-1}$. This may be large enough to expect some dependence of the intersystem crossing rate constant upon deuteration due to changes in the Franck-Condon overlap factor. The absence of a normal deuteration effect as found in the present work is consistent with a $S_{1} \rightarrow T_{2}$ intersystem crossing process for dilute solutions of $p$-xylene and toluene.

Assuming $k_{\mathrm{FM}}$ and $k_{\mathrm{TM}}$ to be practically constant with temperature [16], the effect of temperature on fluorescence can be analysed using the expression

$1 / \phi_{\mathrm{FM}}=1+k_{\mathrm{TM}} / k_{\mathrm{FM}}+\left(k_{\mathrm{GM}}^{\prime} / k_{\mathrm{FM}}\right) \exp \left(-w_{\mathrm{GM}} / k T\right)$, in which $k_{G M}^{\prime}$ and $W_{G M}$ are respectively the frequency factor and activation energy for the nonradiative transition $S_{1} \rightarrow S_{0}$. Using the fluorescence results obtained in this work and triplet yields determined by Cundall and co-workers [16,22] we obtain $k_{\mathrm{GM}}=3.15 \times 10^{11} \mathrm{~s}^{-1}$ and $w_{\mathrm{GM}}=0.24 \mathrm{eV}$ for toluene and $k_{\mathrm{GM}}=3.2 \times 10^{9}$ $\mathrm{s}^{-1}$ and $w_{G M}^{\prime}=0.22 \mathrm{eV}$ for $p$-xylene. The frequency factors and activation energies are reasonably comparable with the corresponding values reported for liquid benzene solutions $[4,15]$ and suggest a spin-allowed character for channel 3 . Further results of triplet yields for toluene- $d_{8}$ and $p$-xylene- $d_{10}$ may indicate whether perdeuteration is relevant to the nonsadiative transition $S_{1} \rightarrow S_{0}$.

\section{Acknowledgement}

The authors gratefully acknowledge partial financial support from a NATO grant and facilities provided by the Physics Department at the University of Lourenço Marques rvhere part of this work was carried out. 


\section{References}

[i] M.F. Thomaz, I. Barradas and J.A. Ferreirz, J. Luminescence 11 (1975) 55.

[2] J.N. Demas and A.W. Adamson, J. Phys. Chem. 75 (1971) 2463.

(3) M.D. Lumb, C. Lloyd Braga and L.C. Pereira, Trans. Faraday Soc. 65 (1969) 1992:

M.D. Lumb, M.I. Barrada, L.C. Pereira and C. Lloyd Braga, Rev. Fis, Quim. Fng. U.L.M. 1 (1969) 1.

[4] L.C. Pereira, Ph.D. Thesis, University of Nottingham (1972).

[5] M. Almgren, Photochem. Photobiol. 8 (1968) 231.

[6] M.D. Lumb, Rev. Fís. Quim. Eng. U.LM. 1 (1970) 1; J.N. Demas and G.A. Crosby, J. Phys. Chem. 75 (1971) 991.

[7] W.W. Maintulin and J.R. Huber, Photochem. Photobiol. 17 (1973) 139.

[8] E.D. Cehelnik, K.D. Mielenz and R.A. Velapoldi, J. Res. Natl. Bur. Std. US 79A (1975) 1.

[9] I.B. Berlman, Handbook of fluorescence spectra of aromatic molecules (Academic Press, No:w York, 1971).

[10] M.D. Lumb and D.A. Weyl, J. Mol. Spectry. 23 (1962) 365.

[11] P.M. Froelich and H.A. Morrison, J. Phys, Chem. 76 (1972) 3566.

[12) C.D. Amata, M. Burton, W.P. Helman, P.K. Ludwig and S.A. Rodemayer, J. Chem. Phys. 48 (1968) 2374.

[13] R.B. Cundall and S. MCD. Ogilvie, in: Organic molecular photophysics, Vol 2, ed. J.B. Birks (Wiley-Interscience, New York, 1974) pp. 33-93.

[14] R.B. Cundall, D.A. Robinson and L.C. Pereira, submitted for publication.
[15] J.B. Birks, ed., Organic molecular photophysics, Vol. 2 (Wiley-Interscience, New York, 1974).

[16] R.B. Cundall, LC. Pereira and D.A. Robinson, J. Chem. Soc. Faraday II 61 (1973) 701.

[17] R. B. Cundall and D.A. Robinson, J. Chem. Soc. Faraday II 68 (1972) 1145, 1323.

[18] R.B. Cundall and L.C. Pereira, Chem. Phys Letters 16 (1972) 371.

[19] K. Sandros, Acta Chem. Scand. 25 (1971) 3651.

[20] J.B. Birks, Photophysics of arematic molecules (WileyInterscience, New York, 1970); J.B. Birks, ed., Organic molecular photophysics, Vol. 1 (Wilcy-Interscience, New York, 1974).

[21] S.J. Formosinho, J. Chem. Soc. Faraday II 70 (1974) 605; S.J. Formosinho and J. Dias da Silva, Mol. Photochem. 6 (1974) 409.

[22] R.B. Cundall and S. McD. Ogivie, to be published.

[23] B. Sharf, J. Chem. Phys. 55 (1971) 320, and references thescin.

[24] E.C. Lim and H.B. Bhattacharjee, Chem. Phys. Letters 9 (1971) 249; J. Chem. Phys. SS (1971) S126, and references therein.

[25] G.M. Breuer and E.K.C. Lee, J. Chem. Phys. 51 (1969) 3615:

B.K. Selinger and W.R. Ware, J. Chem. Phys. 53 (1970) 3160.

[26] R.B. Cundall, L.C. Pereira and D.A. Kobinson, Chem. Phys. Letters 13 (1972) 253:

R.B. Cundall, S. McD. Ogilvie and D.A. Robinson, J. Photochem. $1(1972 / 73) 417$.

[2?] B. Sharf and R. Sibey, Chem. Phys. Letters 5 (1970) 314. 